\title{
Immunoglobulins and complement in pleural effusions associated with bronchogenic carcinoma
}

\author{
A. B. KAY, ${ }^{1}$ A. F. SMITH, ${ }^{2}$ C. R. McGAVIN, ${ }^{3}$ AND SUSAN B. TUFT ${ }^{3}$ \\ From the South-East Scotland Regional Blood Transfusion Service, Royal Infirmary, Edinburgh ${ }^{1}$, \\ the University Department of Clinical Chemistry, Royal Infirmary, Edinburgh, ${ }^{2}$ and the University \\ Department of Respiratory Diseases, City Hospital, Edinburgh ${ }^{3}$
}

SYNOPSIS Levels of IgG, IgA, IgM, the total haemolytic complement $\left(\mathrm{CH}_{50}\right)$, and the individual components $\mathrm{Clq}, \mathrm{C} 3, \mathrm{C} 4, \mathrm{C} 6$, and $\mathrm{C} 7$ were measured in 29 pleural effusions. Of these, 18 were associated with carcinoma of the bronchus and 11 were non-malignant effusions including empyemas.

The level of IgG was significantly lower in the malignant group when compared with nonmalignant effusions. The usefulness of measurements of IgG with respect to malignant effusions associated with carcinoma of the bronchus requires an expanded study to show whether it has any real diagnostic value. There were no significant differences in other immunoglobulins, the $\mathbf{C H}_{50}$, and individual complement components between the two groups.

The identification of total haemolytic activity in the majority of effusions in both groups indicates that all nine components of the classical pathway of complement, including macromolecules such as $\mathrm{Cl}$, can be present in pleural fluids.

There have been relatively few reports on measurements of immunoglobulins and complement in pleural fluid. Hunder et al (1972) found that the total haemolytic complement $\left(\mathrm{CH}_{50}\right), \mathrm{C} 4$, and $\mathrm{C} 3$ concentrations were lower in the pleural fluids from patients with rheumatoid arthritis and systemic lupus erythematosus than in fluids from patients with malignant and other diseases. Hirsch et al (1971) reported the presence of immunoglobulins IgG, IgA, and IgM in nine pleural fluids in amounts comparable to those concentrations present in the serum.

Since there have been a number of reports which suggest that cancer patients have circulating antigenantibody complexes which in turn may lead to activation of complement, we have measured immunoglobulins and individual complement components in 18 malignant pleural fluids and compared these with 11 non-malignant effusions, including empyemas.

\section{Material and methods}

\section{PLEURAL EFFUSIONS}

Samples were centrifuged at $1500 \mathrm{~g}$ to remove parti-

Received for publication 3 March 1976 culate matter, divided into portions, and kept at $-80^{\circ} \mathrm{C}$. The effusions were processed and stored on the same day as the pleural aspiration and were thawed only once before each assay.

TOTAL PROTEIN

This was measured by a standard AutoAnalyzer (Technicon Instruments Corporation Ltd, Basingstoke) method (N14b) which uses the biuret reaction. The between-batch precision ( \pm 1 SD) was $1.0 \mathrm{~g} / 1$.

IgG, IgA, AND IgM

These were measured by an automated nephelometric procedure on an AutoAnalyzer II (method no. 12). The method incorporates $4 \%$ polyethylene glycol in the antiserum diluent. Samples were prediluted manually $(1: 50$ for $\operatorname{IgA}$ and $\operatorname{IgM}$, and $1: 200$ for IgG) rather than on the AutoAnalyzer. The between-batch precision $( \pm 1 \mathrm{SD})$ in the range up to $300 \mathrm{IU} / \mathrm{ml}$ was $8.0 \mathrm{IU} / \mathrm{ml}$ for IgG, $12.6 \mathrm{IU} / \mathrm{ml}$ for $\mathrm{IgA}$, and $7.0 \mathrm{IU} / \mathrm{ml}$ for $\mathrm{IgM}$.

\section{COMPLEMENT}

The haemolytic complement $\left(\mathrm{CH}_{50}\right)$ was measured by the method of Mayer (1961). Levels of complement components $\mathrm{Clq}$ and $\mathrm{C} 3$ were measured by single radial diffusion using monospecific antisera 
raised in the rabbit. Levels of $\mathrm{C} 4$ and $\mathrm{C} 6$ were measured using C4-deficient guinea-pig and C6deficient rabbit sera respectively (Lachmann et al, 1973), and C7 was measured by the reactive lysis method (Thompson and Lachmann, 1970). Immunoelectrophoresis was performed as described (Scheidegger, 1955) using a rabbit antiserum to human plasma proteins purchased from Wellcome Reagents Ltd.

\section{Results}

When the electrophoretic pattern of malignant and non-malignant pleural effusion, including empyemas, was compared to the pattern of normal serum there were no major differences in the number of positions of the principal protein bands.

The amount of Ig Gper milligram total protein in the malignant effusions was significantly $(P<0.01)$ lower than the IgG content of the nonmalignant group (fig 1). The differences in IgA and IgM per milligram of total protein and in total protein concentration itself between the two groups were not significant.

Total haemolytic complement was measurable in the majority of pleural effusions but there was no significant difference in levels between the malignant and nonmalignant fluids (fig 2). The individual components $\mathrm{C} 1 \mathrm{q}, \mathrm{C} 4, \mathrm{C} 3, \mathrm{C} 6$, and $\mathrm{C} 7$ were also detectable in the majority of effusions but no significant differences were found between the two groups (fig 2).

\section{Discussion}

In the report by Hirsch et al (1971), three out of the nine pleural effusions were from patients with

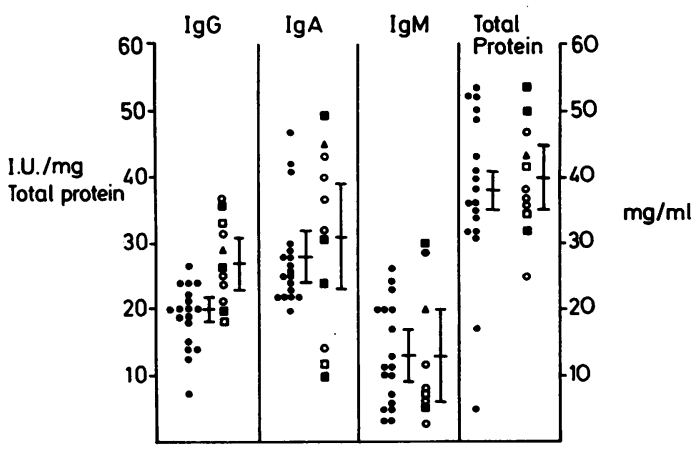

Fig 1 Immunoglobulins and total protein in malignant and nonmalignant pleural effusions. Malignant effusions (O), empyema (O), tuberculosis $(\square)$, pneumonia $(\square)$, pulmonary infarction ( $\mathbf{\Delta})$.

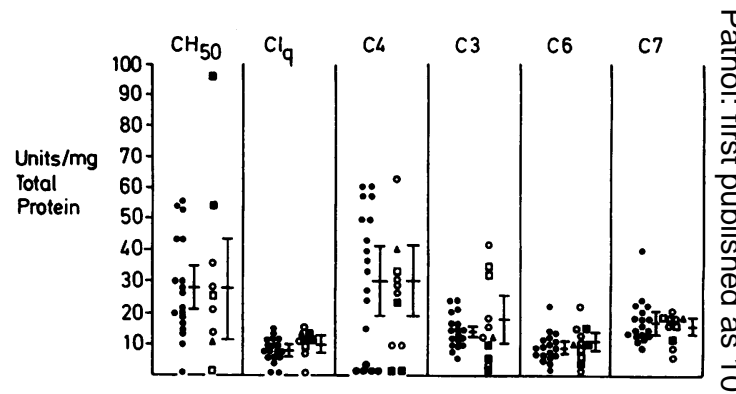

Fig 2 Total haemolytic complement $\left(\mathrm{CH}_{50}\right)$ and the individual complement components $\mathrm{Clq}, \mathrm{C4}, \mathrm{C3}, \mathrm{C6}$, and $C 7$ in malignant and nonmalignant pleural effusions. Malignant effusions (O), empyema $(\bigcirc)$, tuberculosis $(\square)$, pneumonia $(\square)$, pulmonary infarction $(\Delta)$.

carcinoma of the lung, but in this small series the levels of IgG, IgA, and IgM were not markedly ${ }_{0}$ depressed when compared with nine nonmalignant $\stackrel{\circ}{工}$ fluids. Our findings show that the amount of IgG $\vec{O}$ per milligram of total protein in malignant effusions was significantly lower than the IgG content of the $\frac{0}{0}$ nonmalignant fluids, but there was considerable $\stackrel{\mathbb{}}{-}$ overlap between the two groups (fig 1). This observa- $\vec{\theta}$ tion may, however, have relevance when very lo\& IgG concentrations are present although further studies are necessary to evaluate the real diagnost value of these findings. Immunoelectrophoresit alone does not appear to have diagnostic value as the patterns were similar with each disease state.

The reasons for the lower concentration of IgG $\stackrel{\mathbb{Q}}{2}$ in the malignant group is unknown. One explanation $\overrightarrow{\overrightarrow{0}}$ is that IgG is an inadvertent substrate for plasmin 3 as a result of local fibrin formation and activation of the fibrinolytic pathway. Disseminated intravascular coagulation (DIC) in association with disseminated carcinoma is well recognized. Although DIC was:not a complication in any of the patients studied 3 . here it is possible that there was low-grade conversion of plasminogen by a plasminogen activator in the pleural space of the patients with carcinoma. 0 Levels of fibrin degradation products were higher in pleural fluids from patients with carcinoma than in nonmalignant fluids (J. D. Cash, personal communication).

Although we did not have the opportunity to N measure plasma concentrations of immunoglobulins $N$ at the time of pleural aspirations, it is unlikely that ${ }_{\sigma}^{\omega}$ our findings merely reflect low circulating $\operatorname{IgG}$ levels. In a report by Hughes (1971) IgG levels in cancer patients, including those with bronchogenic carcinoma, were significantly increased when com $-\stackrel{-}{-}$ pared with those in matched controls.

Measurements of the $\mathrm{CH}_{50}$ and individual com- $-\stackrel{\overrightarrow{\mathrm{D}}}{\mathrm{D}}$ ponents in body fluids other than plasma have $\frac{\mathbb{P}}{\mathbb{Q}}$ 
been of value diagnostically. The complement levels in joint effusions in systemic lupus erythematosus (SLE) and rheumatoid arthritis (RA) have been found to be lower than in 'non-rheumatoid' arthritis fluids from patients with osteoarthritis or gout (Pekin and Zvaifler, 1964; Franco and Schur, 1971). Similarly, the $\mathrm{CH}_{50}, \mathrm{Clq}, \mathrm{C} 3$, and $\mathrm{C} 4$ were lower in pleural fluids secondary to SLE and RA than in malignant pleural effusions (Hunder et al, 1972). These findings are thought to be a consequence of complement activation by antigen-antibody complexes. Since there is evidence in both man and experimental animals for the presence of immune complexes in cancer (Baldwin et al, 1974), in this study we have measured complement in malignant effusions and have included the terminal components C6 and C7. We have compared our malignant group with exudates associated with pneumonia, tuberculosis, and pulmonary infarction and with empyemas. Although we found no significant difference between our two groups in terms of complement measurements (fig 2), the observation that many of these components were present adds to knowledge of the composition of pleural fluids.

The mechanism by which fluid accumulates within the pleural cavity is incompletely understood. Leckie and Tothill (1965) found that radiolabelled albumin can diffuse freely out of the pleural space, and it seems likely that most proteins in pleural effusions derive from the circulation as a result of the inflammatory process rather than from local production. It is reasonable to suppose that macromolecules, such as C1 (molecular size 900000 ), can diffuse into the pleura. The majority of fluids from the malignant and nonmalignant groups had total complement activity (the $\mathrm{CH}_{50}$ ) which requires $\mathrm{C} 1$ and the other components of the 'classical pathway'.
We are grateful to Dr Margaret Calder, Bacteriology Laboratories, City Hospital, Edinburgh, for supplying us with pleural fluids, and to the numerous clinicians who agreed to provide specimens. Part of this work was supported by a grant from the Scottish Home and Health Department.

\section{References}

Baldwin, R. W., Bowen, J. G., Embleton, M. J., Price, M. R., and Robins, R. A. (1974). Cellular and humoral immune responses to neoantigens associated with chemicallyinduced tumours. In Progress in Immunology II, edited by L. Brent and J. Holborow, Vol. 3, pp. 239-248. NorthHolland, Amsterdam.

Franco, A. E. and Schur, P. H. (1971). Hypocomplementemia in rheumatoid arthritis. Arthr. and Rheum., 14, 231-238.

Hirsch, A., Papiernik, M., Saint-Paul, M., Bonnaud, G., and Chrétien, J. (1971). Exploration de certaines réactions immunitaires au cours des épanchements pleuraux. Presse méd., 79, 2421-2426.

Hughes, N. R. (1971). Serum concentrations of $\gamma \mathrm{G}, \gamma \mathrm{A}$, and $\gamma \mathbf{M}$ immunoglobulins in patients with carcinoma, melanoma, and sarcoma. J. nat. Cancer. Inst., 46, 1015-1027

Hunder, G. G., McDuffie, F. C., and Hepper, N. G. G. (1972). Pleural fluid complement in systemic lupus erythematosus and rheumatoid arthritis. Ann. intern. Med., 76, 357-363.

Lachmann, P. J., Hobart, M. J., and Aston, W. P. (1973). Complement technology. In Handbook of Experimental Immunology, edited by D. M. Weir, Chapter 5. Blackwell, Oxford.

Leckie, W. J. H. and Tothill, P. (1965). Albumin turnover in pleural effusions. Clin. Sci., 29, 339-352.

Mayer, M. M. (1961). Complement and complement fixation. In Experimental Immunochemistry, edited by E. A. Kabat and M. M. Mayer, 2nd edition, pp. 33-240. Thomas, Springfield, Illinois.

Pekin, T. J., Jr. and Zvaifler, N. J. (1964). Hemolytic complement in synovial fluid. J. clin. Invest., 43, 1372-1382.

Scheidegger, J. J. (1955). Une micro-méthode de l'immunoélectrophorèse. Int. Arch. Allergy, 7, 103-110.

Thompson, R. A. and Lachmann, P. J. (1970). Reactive lysis: the complement-mediated lysis of unsensitized cells. I. The characterization of the indicator factor and its identification as C7. J. exp. Med., 131, 629-641. 